\title{
22 | 2020
}

74. Jahrgang

20. November 2020

S. $1345-1408$

PVSt 4954
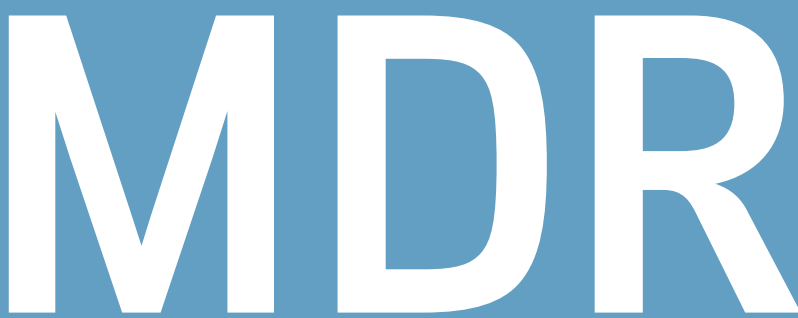

\section{Monatsschrift für Deutsches Recht}

Zeitschrift für Zivil- und Zivilverfahrensrecht

mdr-recht.de

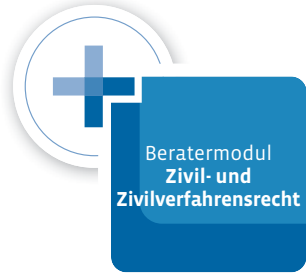

Profitieren Sie von Ihrer ONLINE-DATENBANK
Aufsätze > Hans-Willi Laumen - Verkehrsunfall: Der Anscheinsbeweis im

Straßenverkehrsrecht (Teil 1) 1345

Ernst Führich - Fluggastrechte: Die Entwicklung des Reiserechts der Luftbeförderung einschließlich der EU-Fluggastrechte-VO im Jahre 2019

Natalie Post - Gutgläubiger Erwerb: Besitzlage bei Probefahrten und in weiteren Vertragsanbahnungssituationen

Prozessrecht aktiv > Sachverständiger: Anweisung zur Vornahme einer Bauteilöffnung (BGH, Urt. v. 23.9.2020 - IV ZR 88/19, MDR 2020, 1391) Oliver Seggewiße

Klauselerteilungsverfahren: Rechtsmittel des Rechtsnachfolgers gegen Verweigerung (BGH, Beschl. v. 26.8.2020 - VII ZB 39/19, MDR 2020, 1337) Uwe Salten

Gerichtsstandsbestimmung: Zulässigkeit bei einer subjektiven Klageerweiterung nach Erhalt der Klageerwiderung (BGH, Beschl. v. 14.7.2020 - X ARZ 156/20, MDR 2020, 1397) Christoph Fellner

Rechtsprechung > WEG-Recht: Auswirkung der Corona-Pandemie auf Veräußerungszustimmung des WEG-Verwalters (OLG Hamm, Beschl. v. 5.8.2020 15 W 266/20)

Kfz-Recht: Unterschlagung eines Autos während Probefahrt durch vermeintlichen Kaufinteressenten (BGH, Urt. v. 18.9.2020 - V ZR 8/19)

Bankrecht: Kein Außergeschäftsraum-Widerrufsrecht bei Bürgschaft (BGH, Urt. v. 22.9.2020 - XI ZR 219/19)

Verfahrensrecht: Wiedereinsetzung in den vorigen Stand mangels gerichtlichen Hinweis auf Fehlen der einfachen Signatur (BAG, Beschl. v. 14.9.2020 - 5 AZB 23/20) 


\section{Kosteneffizient}

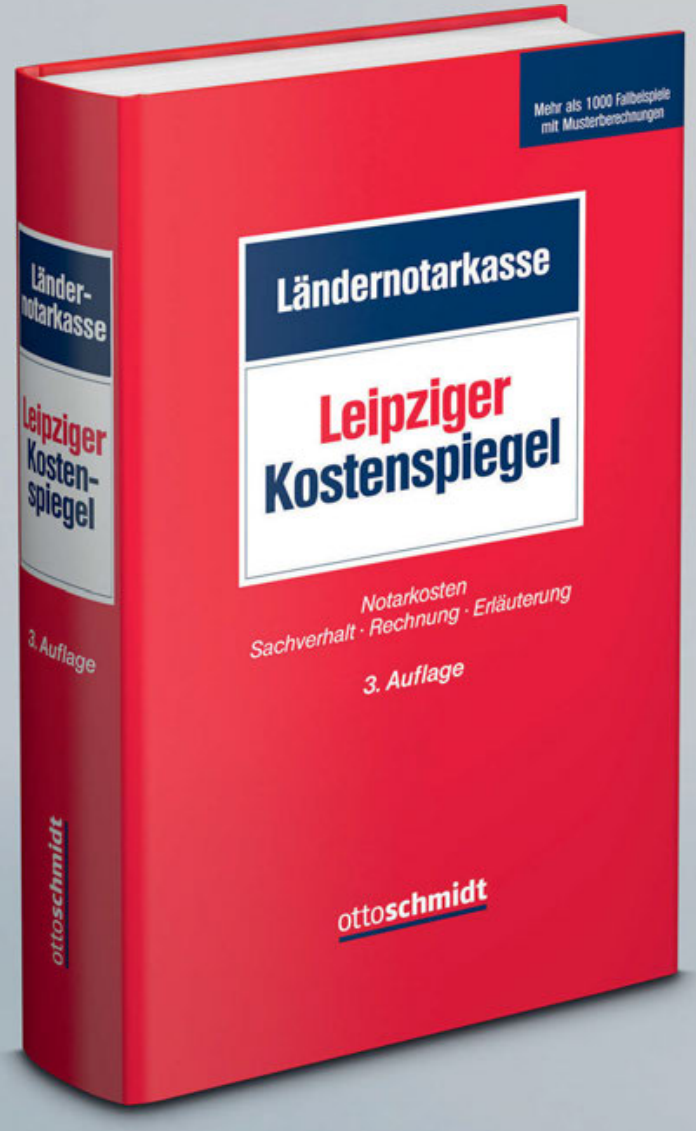

Ländernotarkasse Leipziger Kostenspiegel Notarkosten

Sachverhalt - Rechnung - Erläuterung

3. völlig neu bearbeitete Auflage, 2020,

ca. 1.630 Seiten, gbd. $89,80 €$

Erscheint im Oktober

ISBN 978-3-504-06765-6

(i) Das Werk online otto-schmidt.de/notbz juris.de/notare
Der Leipziger Kostenspiegel bietet einen besonderen Ansatz, kostenrechtliche Probleme im Notariat sicher zu lösen: Perfekt strukturiert nach den jeweiligen Tätigkeiten des Notars werden zu allen denkbaren Konstellationen die sich jeweils ergebenden Kostenfolgen abgebildet. Auf diese Weise führt das Buch, immer orientiert am „Echtfall“, in mehr als 1000 konkreten Berechnungsbeispielen vom Kosten auslösenden Tatbestand zur richtigen Lösung.

Die Neuauflage ist topaktuell und wurde um viele neue Fallgestaltungen erweitert, wesentlich ausgebaut wurden die Bewertungsbeispiele zum Versorgungsausgleich und zum Unterhalt. Schon berücksichtigt sind die aktuellen BGH-Entscheidungen zur GmbH-Gesellschafterliste und den Auswirkungen neuer Sicherungssysteme auf das Kostenrecht, insbesondere die Sicherung des Grundstücksverkäufers durch eine bedingte Eintragungsbewilligung.

Leseprobe und Bestellung www.otto-schmidt.de 